\title{
FLOOD RISK ZONATION USING A MULTI-CRITERIA SPATIAL GROUP FUZZY-AHP DECISION MAKING AND FUZZY OVERLAY ANALYSIS
}

\author{
M. Hasanloo ${ }^{1}$, P. Pahlavani ${ }^{1, *}$, B. Bigdeli ${ }^{2}$ \\ ${ }^{1}$ School of Surveying and Geospatial Engineering, College of Engineering, University of Tehran, Tehran, Iran- (hasanloomohamad, \\ pahlavani)@ut.ac.ir \\ ${ }^{2}$ School of Civil Engineering, Shahrood University of Technology, Shahrood, Iran - bigdeli@ shahroodut.ac.ir
}

KEY WORDS: Flood risk map, Fuzzy AHP, Fuzzy reclassification, Fuzzy overlay analysis

\begin{abstract}
:
In this study, a GIS based approach has been proposed for the flood risk zonation based on a multi-criteria spatial group fuzzy AHP decision making analysis and its integration with fuzzy overlay analysis. For this purpose, 10 layers affecting flood occurrence have been used including: the Digital Elevation Model (DEM), Slope, NDVI, Flow Accumulation (Flow Ac.), HOFD, VOFD, Topographic Position Index (TPI), Topographic Wetness Index (TWI), Curve Number (CN), Modified Fournier Index. Each layer was classified into 5 sub-classes and their preference at its layer was weighted by a group of experts using fuzzy analytical hierarchy processes (GFAHP) method. Finally, the risk map of the studied area with the weight of experts and fuzzy overlay method was product and divided into five categories.
\end{abstract}

\section{INTRODUCTION}

Flooding is one of the most devastating and costly natural events in all countries, causing lots of damages. The development of urbanization, especially in the riversides, as well as the human and financial losses due to the floods, indicate the need to provide maps of flood risk areas. According to statistics compiled by the United Nations in the midst of natural disasters, floods and storms inflicted the greatest casualties and damages to human communities. In a decade between 2000 and 2010, the amount of damage caused by flooding and the hurricane amounted to $\$ 21$ billion against $\$ 18$ billion in damage caused (AmirAhmadi et al. 2011). The flood risk zoning map can be used as an effective tool for planning the development of the city by the Minister of Construction (Buchele et al., 2006). Geospatial information systems (GIS), remote sensing, and Multi-criteria decision analysis propose techniques and methods for solving complicated problems that their criteria are often not comparable (Rashed and weeks, 2003; Gamper, et al. 2006; Delavar, 2004; Pahlavani et al., 2006; Pahlavani et al., 2017; Bahari et al., 2014; Bigdeli et al., 2013; Bigdeli et al., 2014). There have been several studies on flood risk zoning. Hyalmarson (1988) investigated the hazards of engineering operations to zoning flood risk in western and eastern Arizona using hydrological and geomorphological features. Liang and Mohanty (1997) introduced and optimized flood management based on zoning as a non-flood control method. Using the remote sensing data from the 1988 historical flood, Islam and Kimitero (2000) prepared a flood risk map for Bangladesh. They overlapped two digital flood risk maps using land cover, physiographic and geological classification data and prepared a flood risk map.

Correia et al. (1995) applied GIS, hydrological and hydraulic models in floodplains and urban development to evaluate the impact of land use control on flood risk. Fernandez and Lutz (2010) zoned the city of Yerba Buena, Argentina in terms of flood risk using GIS and multi-criteria decision making system. They used the parameters of distance to drainage channels, area height, slope area, groundwater depth and land use. Multi-criteria decision making system was applied for determination of weights for each of five factors. They zoned their area into five zones with high risk, medium to high risk, medium risk, low risk and very low risk.

Ozturk and Batuk (2011) introduced GIS-MCDA with the help of Geographic Information System and Multi-Criteria Decision Making System, which is known as the Turkish Marmara area zoning program. This zoning has been done by selecting and providing effective layers including annual rainfall, subcatchment area, elevation, slope, slope direction and drainage coefficient in creating flood zone. These layers were compared in the environment and the final GIS-MCDA coefficient was determined. The final AHP-based map for each layer divided the zones at high, high, medium, low and very low flood risk by the value of each pixel.

Moreli et al. (2012) investigated the potential of the Arno River flooding in Italy by navigating the river pattern in different areas using GPS and GIS, and concluded that areas with urban development were more at risk. Maantay and maroko (2009) zoned New York in terms of time span of different floods. Chen et al. (1997) developed a GIS-based urban flood model using cumulative surface runoff and rainfall runoff. Asgharpour and Ajdari (2011) studied seasonal floods in Iran's Qatari Watershed. AL-Ghamdi et al. (2011) Zoned Mecca using spatial analysis in GIS for flood risk based on two major floods of years 1990 and 2010 and obtained a map of the potential flooding in different areas of the city.

In this paper a GIS-based approach has been proposed for flood risk zonation using a spatial group fuzzy AHP multi-criteria decision making analysis and fuzzy overlay analysis. 


\section{DATA AND METHOD}

\subsection{Study Area}

Maneh and Samalgan are from the northern Khorasan province with an area of $4898 \mathrm{~km}^{2}$ and a population of 103944 people. The city of Maneh and Samalghan is geographically divided into mountainous and plain areas, the mountainous part of which is in the West and Southwest and plain area in the North and Center of the province. Figure 1 shows the study area.

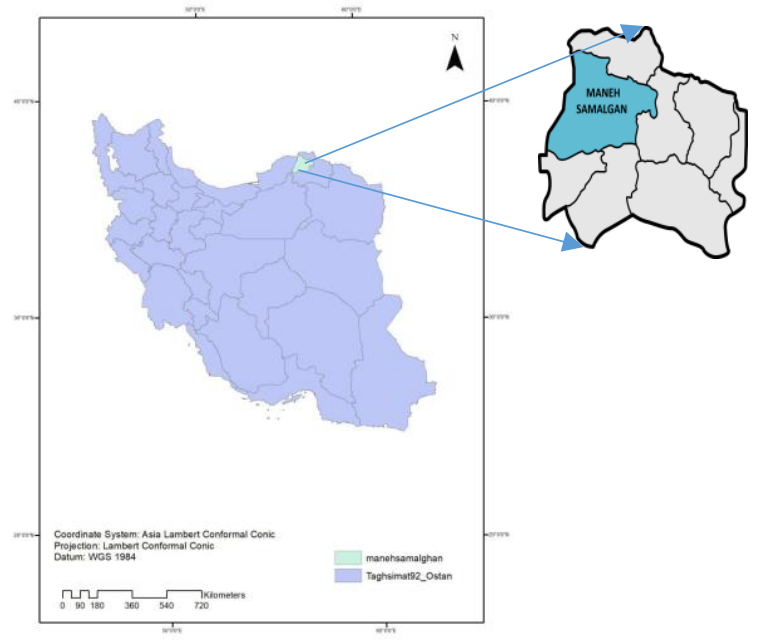

Figure 1 . The study area

\subsection{Proposed methodology}

At first, the correlation matrix of generated spatial was calculated and the non-correlated layers were identified in the occurrence of flood and each layer was divided into 5 sub-layers. Then, using a group of experts for each sub-layer a weight was allocated using fuzzy AHP method. Each sub-layer was reclassified with the new achieved fuzzy AHP weighted. Accordingly, a Large fuzzy membership function prepared layers in order to apply them in fuzzy Gamma overlay. Finally, with fuzzy overlay, the flood risk map was produced and classified into 5 categories. The flowchart of the proposed method is shown in Figure 2.

\subsubsection{Producing effective spatial layers}

In this study, 10 spatial layers affecting flood occurrence have been used including: The Digital Elevation Model (DEM), Slope, NDVI, Flow Accumulation, HOFD, VOFD, Topographic Position Index (TPI), Topographic Wetness Index (TWI), Curve Number $(\mathrm{CN})$, Modified Fournier Index. A brief introduction of these layers are as follows:

1- DEM: The digital elevation model is a 3D representation of a terrain's surface

2- $\mathrm{CN}$ : The curve number is an empirical parameter for predicting direct runoff or infiltration from rainfall excess.

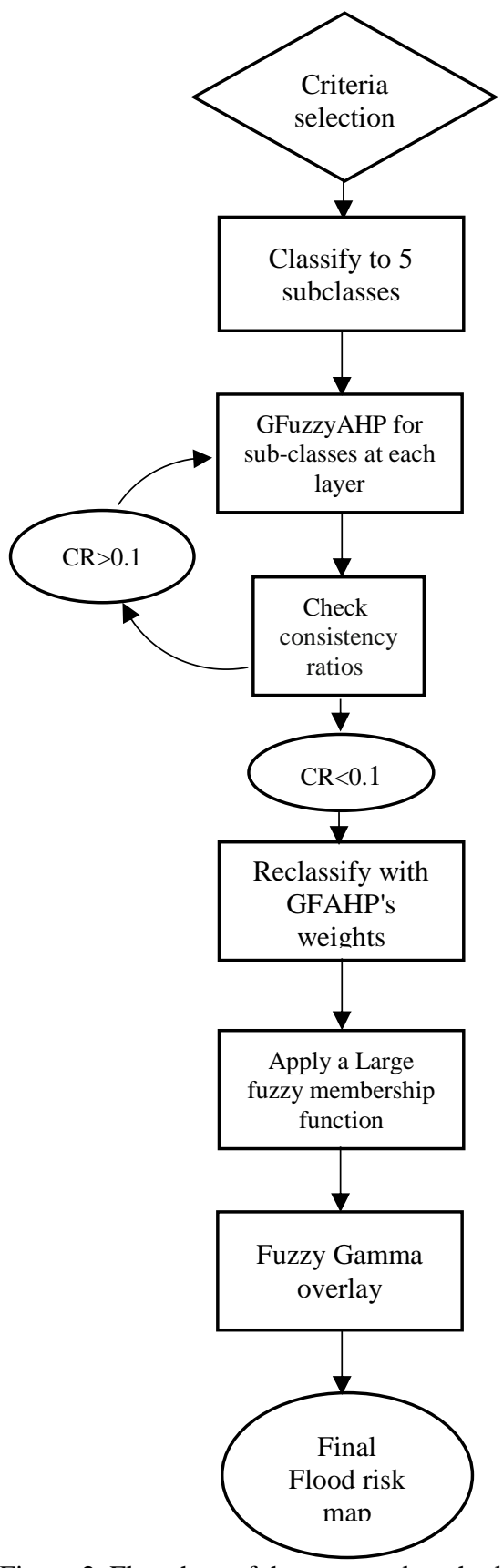

Figure 2. Flowchart of the proposed methodology

3- TPI: The topographic position index (TPI) shows the height difference of each cell with the mean heights of its neighboring cells.

4- TWI: Describes the humidity conditions of the basin.

5- VOFD: Vertical Overland Flow Distance.

6- HOFD: Horizontal Overland Flow Distance.

7- NDVI: It is known as a vegetation cover estimator.

8- MFI: Rainfall intensity maps are generated using the modified Fournier Index (MFI).

9- Flow accumulation: It shows the amount of current that goes from the upper cells to the desired cell.

10- Slope: The steepness value of a ground point.

Figure 3 shows some of these layers. 


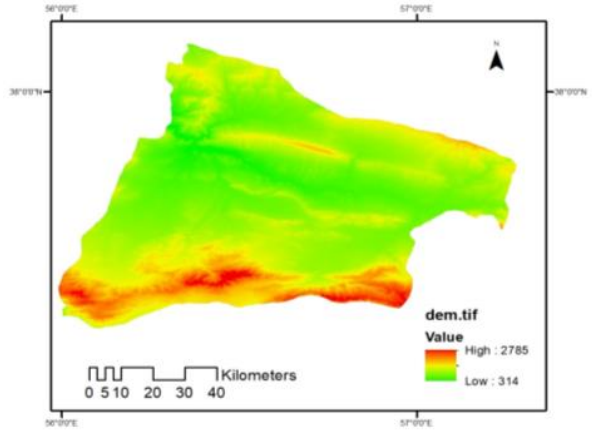

(a) DEM

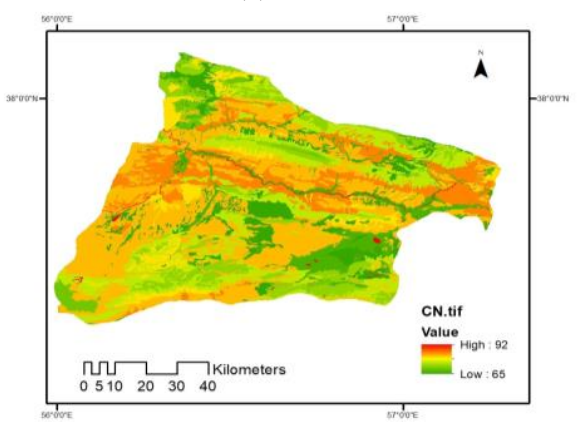

(b) Curve Number

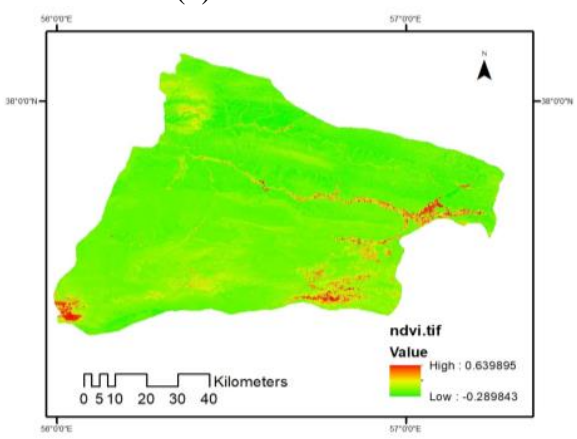

(c) NDVI

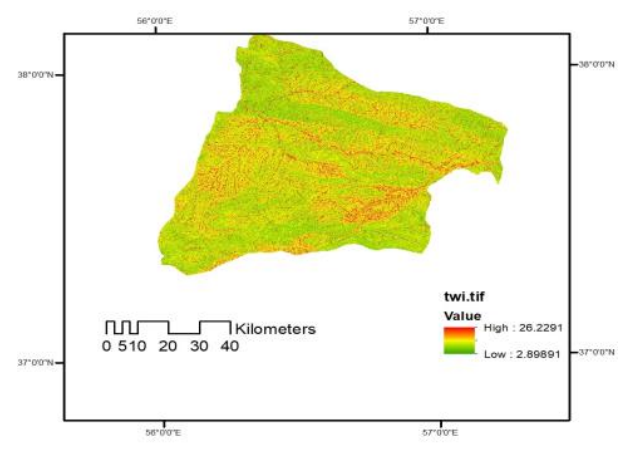

(d) TWI

Figure 3. Some of spatial layers used

\subsubsection{Fuzzy Analytical Hierarchy Process (FAHP)}

Traditional AHP is often criticized for its inability to adequately address the uncertainty associated with mapping decision makers (Deng, 1999). Because fuzziness is a common feature in many decision making problems, a fuzzy AHP (FAHP) method would be able to tolerate ambiguity (Mikhailov and Tsvetinov, 2004). In other words, decision makers are usually more confident about judging distance in the form of single numerical values, hence the FAHP is able to record human assessment ambiguity when complex decision-making problems are considered (Erensal et al., 2006). This ability comes to exist when the crisp judgments transformed into fuzzy judgments. The main feature of fuzziness is individual grouping into classes without sharp boundaries (Hansen, 2005). A triangular fuzzy number is the special class of fuzzy number whose membership defined by three real numbers, expressed as $(l, m, u)$. The triangular fuzzy numbers are as follows:

$$
\mu_{A}(x)=\left\{\begin{array}{cc}
\frac{(x-l)}{m-l} & l \leq x \leq m \\
\frac{(u-x)}{(u-m)} & m \leq x \leq u \\
0 & \text { otherwise }
\end{array}\right.
$$

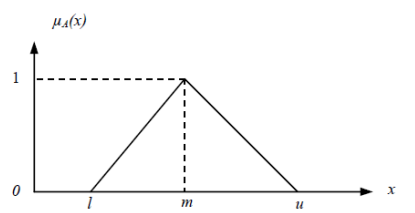

Figure 4. Fuzzy triangular number

The Triangular fuzzy numbers of linguistic variables used in this study are shown in Figure 5.

\begin{tabular}{lll}
\hline Linguistic variables & Triangular fuzzy numbers & $\begin{array}{l}\text { Reciprocal triangular } \\
\text { fuzzy numbers }\end{array}$ \\
\hline Extremely strong & $(9,9,9)$ & $(1 / 9,1 / 9,1 / 9)$ \\
Very strong & $(6,7,8)$ & $(1 / 8,1 / 7,1 / 6)$ \\
Strong & $(4,5,6)$ & $(1 / 6,1 / 5,1 / 4)$ \\
Moderately strong & $(2,3,4)$ & $(1 / 4,1 / 3,1 / 2)$ \\
Equally strong & $(1,1,1)$ & $(1,1,1)$ \\
Intermediate & $(7,8,9),(5,6,7),(3,4,5),(1,2,3)$ & $(1 / 9,1 / 8,1 / 7),(1 / 7,1 / 6,1 / 5)$, \\
& & $(1 / 5,1 / 4,1 / 3),(1 / 3,1 / 2,1)$ \\
\hline
\end{tabular}

Figure 5. Triangular fuzzy numbers of linguistic variables used in this study.

To construct pairwise comparisons under each criterion, a triangular fuzzy comparison matrix is defined as follows:

$$
\tilde{A}=\left(\tilde{a}_{i j}\right)_{n^{*} n}=\left(\begin{array}{lcl}
(1,1,1) & \left(l_{12}, m_{12}, u_{12}\right) & \left(l_{1 n}, m_{1 n}, u_{1 n}\right) \\
\left(l_{21}, m_{21}, u_{21}\right) & (1,1,1) & \left(l_{2 n}, m_{2 n}, u 2 n\right) \\
\vdots & \vdots & \vdots \\
\left(l_{n 1}, m_{n 2}, u_{n 1}\right) & \left(l_{n 2}, m_{n 2}, u_{n 2}\right) & (1,1,1)
\end{array}\right)
$$

where $\quad \tilde{a}_{i j}=\left(l_{i j} \cdot m_{i j} \cdot u_{i j}\right)=\tilde{a}_{i j}{ }^{-1}=\left(\frac{1}{u_{i j}} \cdot \frac{1}{m_{i j}} \cdot \frac{1}{l_{i j}}\right)$

For $i, j=1: n$ and $i \neq j$

In this paper, the weights of alternatives were obtained by 'Fuzzy Extent Analysis' method proposed by Chang (1996) as follows:

Step One: Calculate the normalized value of the row sums as follows:

$$
\tilde{s}_{i}=\sum_{j=1}^{n} \tilde{a}_{i j} \otimes\left[\sum_{k=1}^{n} \sum_{j=1}^{n} \tilde{a}_{k j}\right]^{-1}
$$

where $\otimes=$ the extended multiplication of two fuzzy numbers.

Step Two: Calculate the degree of probability of $\tilde{s}_{i}>\tilde{s}_{j}$ by:

$$
V\left(\tilde{S}_{i}>\tilde{S}_{j}\right)=\operatorname{Sup}_{y \geq x}\left[\min \left(\tilde{S}_{i}(x), \tilde{S}_{j}(y)\right)\right]
$$

that can be equivalently expressed as: 


$$
\mu_{A}(x)=\left\{\begin{array}{c}
1 \quad m_{i} \geq m_{j} \\
\frac{\left(u_{i}-l_{j}\right)}{\left(u_{i}-m_{i}\right)+\left(m_{j}-l_{j}\right)} \quad l_{i} \leq u_{i} \\
0 \text { otherwise }
\end{array}\right.
$$

where $\quad \tilde{S}_{i}=\left(l_{i} \cdot m_{i} \cdot u_{i}\right)$ and $\tilde{S}_{j}=\left(l_{j} \cdot m_{j} \cdot u_{j}\right)$. Figure 5 shows the degree of possibility.

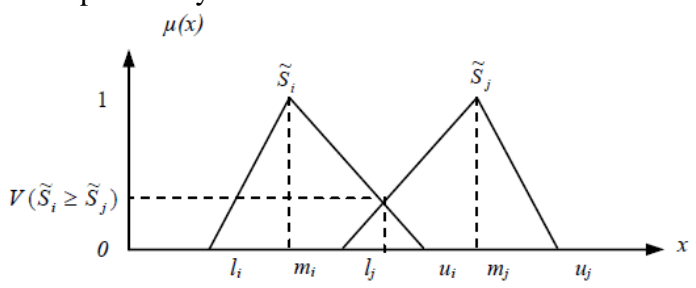

Figure 6.The degree of possibility

Third step: calculating the degree of possibility of $\tilde{s}_{i}$ that is greater than all other fuzzy numbers $\tilde{s}_{j}$ by:

$$
V\left(\tilde{S}_{i}>\tilde{S}_{j} \mid j=1, \ldots, n ; j \neq i\right)=\min V\left(\tilde{S}_{i}>\tilde{S}_{j}\right), i=1, \ldots, n
$$

Fourth step: defining weights by:

$$
w_{i=} \frac{\left(\tilde{S}_{i}>\tilde{S}_{j} \mid j=1, \ldots, n ; j \neq i\right)}{\sum_{k=1}^{n}\left(\tilde{S}_{k}>\tilde{S}_{j} \mid j=1, \ldots, n ; j \neq k\right)}, i=1, \ldots, n
$$

\subsubsection{Fuzzy Reclassification}

The Fuzzy Membership method reclassifies the input data into the range $[0,1]$ based on the possibility of being a member of a specified set. 0 is assigned to those locations that are definitely not a member of the specified set, and 1 is assigned to those that are definitely a member of the specified set. The entire range of possibilities between 0 and 1 are assigned to some level of possible membership (Hersh et al., 1979; Bonham-Carter 1994). This method can include different types of Fuzzy Gaussian, Fuzzy Large, fuzzy Linear, Fuzzy MS Large, Fuzzy MS Small and Fuzzy near. Due to the use of Fuzzy Large type in this study, we investigate this case. The Fuzzy Large transformation function is used when the larger input values are more likely to be a member of the set. The defined midpoint identifies the crossover point (assigned a membership of 0.5 ) with values greater than the midpoint having a higher possibility of being a member of the set and values below the midpoint having a decreasing membership. The spread parameter defines the shape and character of the transition zone. Figure 7 is shows variations of the Fuzzy Large membership function.

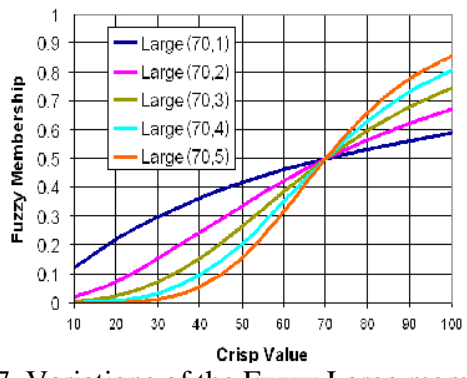

Figure 7. Variations of the Fuzzy Large membership function

\subsubsection{Fuzzy Overlay method}

The Fuzzy Overlay tool allows the analysis of the possibility of a phenomenon belonging to multiple sets in a multicriteria overlay analysis. Not only does Fuzzy Overlay determine what sets the phenomenon is possibly a member of, it also analyzes the relationships between the membership of the multiple sets (Baidya et al., 2014; Akgun et al. 2012). The Overlay type lists the methods available to combine the data based on set theory analysis. Each method allows the exploration of the membership of each cell belonging to various input criteria. The available methods are fuzzy And, fuzzy Or, fuzzy Product, fuzzy Sum and fuzzy Gamma. Due to the use of fuzzy Gamma Type in this study, we investigate this case. The fuzzy Gamma type is an algebraic product of fuzzy Product and fuzzy Sum, which are both raised to the power of gamma. The generalize function is as follows (Baidya et al., 2014):

$$
\mu_{\text {Gamma }}=\left(\prod_{i=1}^{n} \mu_{i}\right)^{1-\gamma}\left(1-\prod_{i=1}^{n}\left(1-\mu_{i}\right)\right)^{\gamma}
$$

If the specified $\gamma$ is 1 , the output is the same as fuzzy Sum; if $\gamma$ is 0 , the output is the same as fuzzy Product. Values within the range $(0,1)$ allow you to combine evidence between these two extremes and possibly different than fuzzy or fuzzy And. Fuzzy Gamma is a compromise of the increasing effect of fuzzy Sum and the decreasing effect of fuzzy Product.

\section{EXPERIMENTAL RESULTS}

Tables 2 to 11 show the results of GFAHP for all spatial layers.

\begin{tabular}{|l|l|l|l|l|l|l|}
\hline DEM & $314_{-}$ & $808_{-}$ & $\begin{array}{l}1302_{-} \\
1796\end{array}$ & $\begin{array}{l}1796_{-} \\
2290\end{array}$ & $2290_{-}$ & CR \\
& $808^{1302}$ & $1305^{-}$ & \\
\hline Weights & 0.374 & 0.266 & 0.145 & 0.136 & 0.079 & 0.023 \\
\hline
\end{tabular}

Table 1. Weights of group FAHP for subclasses of DEM

\begin{tabular}{|l|l|l|l|l|l|l|}
\hline SLOPE & $0_{-}$ & $13.8_{-}$ & $27.6_{-}$ & $41.4_{-}$ & $55.1_{-}$ & CR \\
& 13.7 & 27.5 & 41.3 & 55.1 & 68.9 & \\
\hline Weights & 0.299 & 0.235 & 0.200 & 0.155 & 0.011 & 0.044 \\
\hline
\end{tabular}

Table 3. Weights of group FAHP for subclasses of Slope

\begin{tabular}{|l|l|l|l|l|l|l|}
\hline TPI & $-52.8_{-}$ & $-33.7_{-}$ & $-14.9_{-}$ & $4_{-}$ & $22.9-$ & CR \\
& -33.7 & -14.9 & 4 & 22.9 & 41.9 & \\
\hline Weights & 0.294 & 0.230 & 0.198 & 0.151 & 0.125 & 0.065 \\
\hline
\end{tabular}

Table 4. Weights of group FAHP for subclasses of TPI

\begin{tabular}{|l|l|l|l|l|l|l|}
\hline NDVI & $-0.29-$ & $-33.7_{-}$ & $-0.1_{-}$ & $0.08_{-}$ & $0.45_{-}$ & CR \\
& -0.1 & -14.9 & 0.08 & 0.26 & 0.64 & \\
\hline Weights & 0.320 & 0.268 & 0.195 & 0.120 & 0.095 & 0.078 \\
\hline
\end{tabular}

Table 5. Weights of group FAHP for subclasses of NDVI

\begin{tabular}{|l|l|l|l|l|l|l|}
\hline HOFD & $0_{-}$ & $3.1_{-}$ & $6.1_{-}$ & $9.2_{-}$ & $12.3_{-}$ & CR \\
& 3.1 & 6.1 & $9.2^{-1}$ & 12.3 & 15.4 & \\
\hline Weights & 0.334 & 0.259 & 0.168 & 0.143 & 0.094 & 0.032 \\
\hline
\end{tabular}

Table 6. Weights of group FAHP for subclasses of HOFD

\begin{tabular}{|l|l|l|l|l|l|l|}
\hline VOFD & $0_{-}$ & $278_{-}$ & $557_{-}$ & $836_{-}$ & $1114_{-}$ & CR \\
& 278 & 557 & $836^{-}$ & $1114^{1}$ & 1393 & \\
\hline Weights & 0.326 & 0.233 & 0.198 & 0.144 & 0.097 & 0.046 \\
\hline
\end{tabular}

Table 7. Weights of group FAHP for subclasses of VOFD 


\begin{tabular}{|l|l|l|l|l|l|l|}
\hline FLOW- & $0_{-}$ & 34502 & 69004 & 10350 & 13800 & CR \\
accumula & 34502 & $30-$ & $60-$ & $691-$ & $921-$ & \\
tion & 30 & 69004 & 10350 & 13800 & 1725 & \\
& & 60 & 691 & 921 & 1152 & \\
\hline Weights & 0.311 & 0.239 & 0.205 & 0.176 & 0.066 & 0.030 \\
\hline
\end{tabular}

Table 8. Weights of group FAHP for subclasses of FLOW ACC

\begin{tabular}{|l|l|l|l|l|l|l|}
\hline CN & $65-$ & $70.4-$ & $75.8-$ & $81.2-$ & $86.6-$ & CR \\
& 70.4 & 75.8 & 81.2 & 86.6 & 92 & \\
\hline Weights & 0.254 & 0.240 & 0.200 & 0.169 & 0.134 & 0.053 \\
\hline
\end{tabular}

Table 9. Weights of group FAHP for subclasses of $\mathrm{CN}$

\begin{tabular}{|l|l|l|l|l|l|l|}
\hline TWI & $2.9-$ & $7.56_{-}$ & $12.2_{-}$ & $16.9-$ & $21.5_{-}$ & CR \\
& 7.56 & $12.2^{-}$ & 16.9 & 21.5 & 26.2 & \\
\hline Weights & 0.283 & 0.234 & 0.239 & 0.188 & 0.054 & 0.041 \\
\hline
\end{tabular}

Table 10. Weights of group FAHP for subclasses of TWI

\begin{tabular}{|l|l|l|l|l|l|l|}
\hline MFI & $30.1_{-}$ & $37.6_{-}$ & $45.1_{-}$ & $52.6_{-}$ & $60.1_{-}$ & CR \\
& 37.6 & 45.1 & 52.6 & 60.1 & 67.1 & \\
\hline Weights & 0.273 & 0.244 & 0.239 & 0.199 & 0.156 & 0.058 \\
\hline
\end{tabular}

Table 11. Weights of group FAHP for subclasses of MFI

Also, results of using fuzzy Large membership function for some layers are shown in Figures 8 and 9.

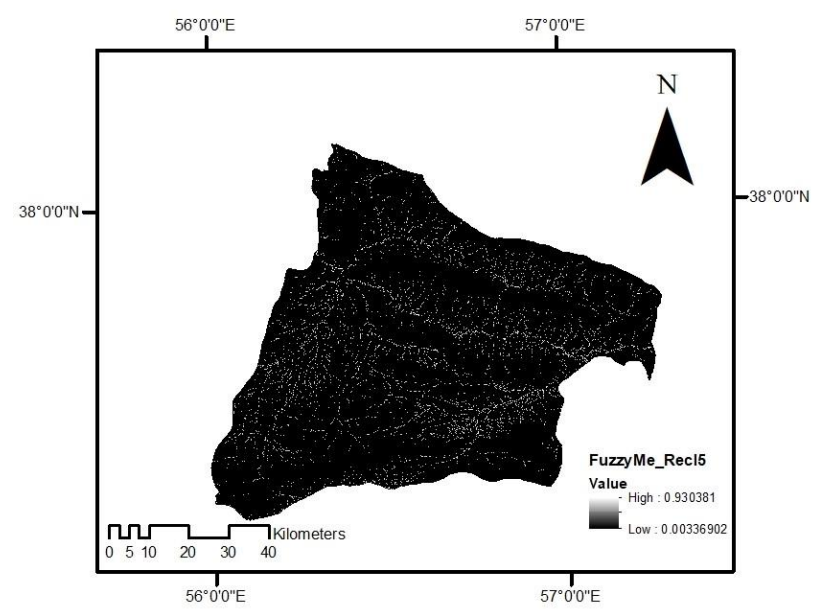

Figure 8. Using Large membership function for TWI layer

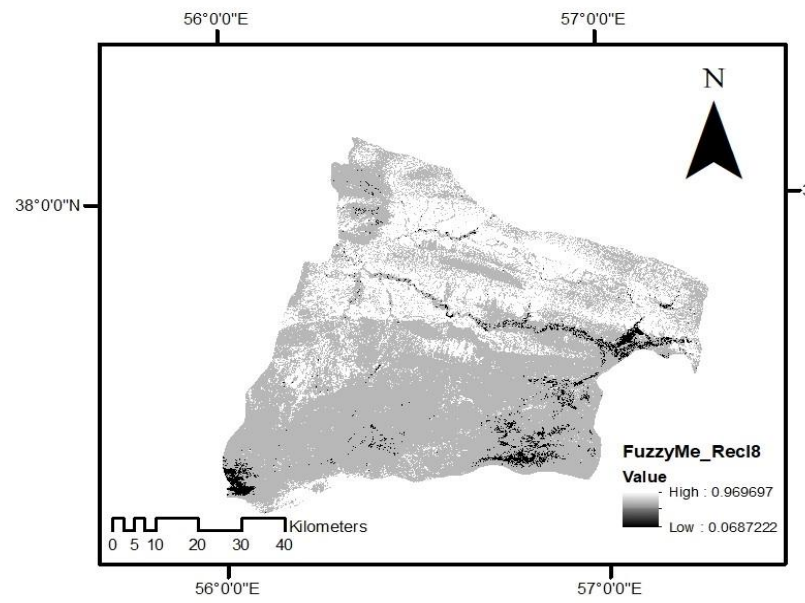

Figure 9. Using Large membership function for NDVI layer

Potential flood risk map was generated by Gamma fuzzy overlay with Gamma equal to 0.85 and classified into five categories: very high risk, high risk, moderate, low risk, and very low risk (Figure 10).

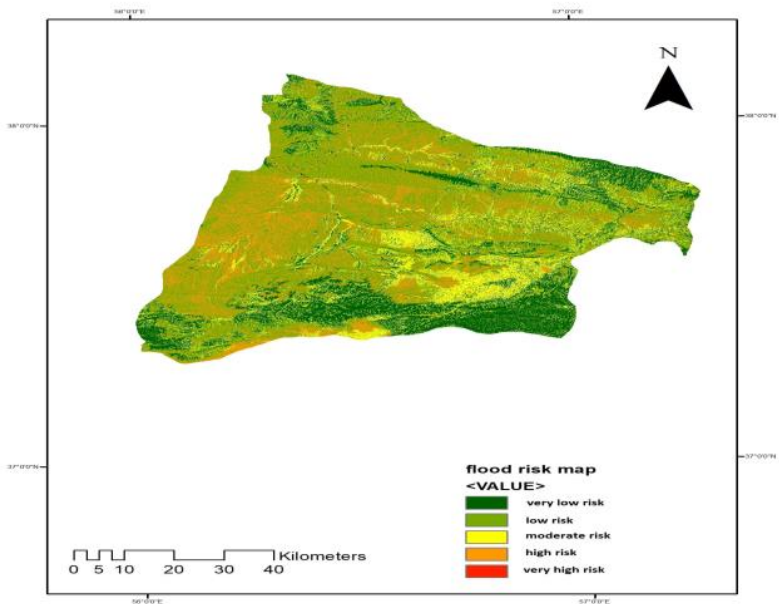

Figure 10. Final flood risk map

Figure 11 shows the flood risk map with $95 \%$ probability.

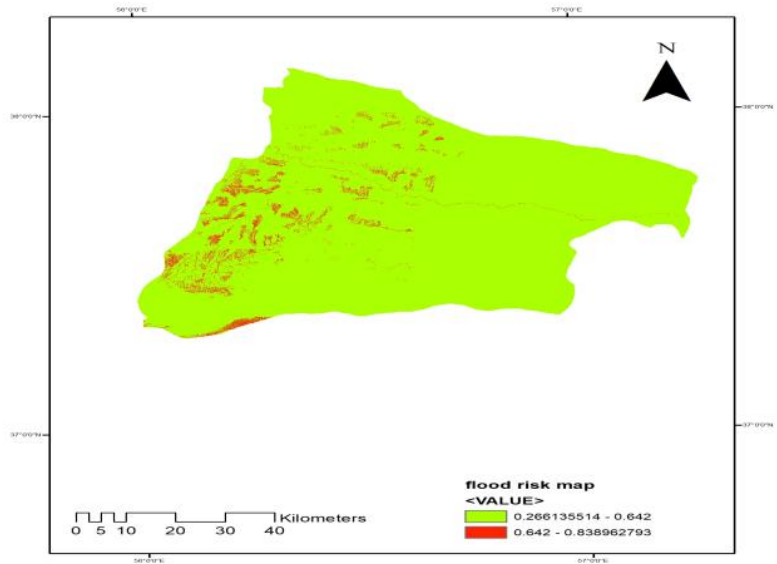

Figure 11 . Flood risk map with $95 \%$ probability

\section{CONCLUSION}

This study examines the role of GIS in a multi-criteria decisionmaking process for flood risk zoning. By integrating GIS and MCDA, the effective factors in the occurrence of flood are better evaluated and by weighing the sub-classes of each layer by the experts, each layer is used more effectively and accurately for flood risk zoning.

Finally, 5.8\% of the area in the study area was in very high risk category, $14.1 \%$ high risk, $15.2 \%$ average risk, $44.3 \%$ low risk and $20.6 \%$ very low risk.

According to the floodiness of the area and the high flood events these maps can be used for crisis management and urban development studies.

\section{REFRENCES}

Akgun A, Sezer EA, Nefeslioglu HA et al. 2012. An easy-to-use MATLAB program (MamLand) for the assessment of landslide susceptibility using a Mamdani fuzzy algorithm. Comput Geosci $38: 23-34$. 
Al-ghamdi, K.A., et al. 2012. GIS evaluation of urban growth and flood hazards: a case study of Makkah city, Saudi Arabia, Knowing to manage the territory, protect the environment, evaluate the cultural heritage, Rome, Italy, PP: 6-10.

AmirAhmadi, A.; Bhniafar, A; M. Ebrahimi. 2011. Flood Hazard Zonation for Sabzevar Urban Sustainable Development. Geographical Journal of Environmental Planning, 16: 33-17

Asheghpoor, S.E., B., Ajdari. 2011. A Case Study on Seasonal Floods in Iran, Watershed of Ghotour Chai Basin, Procedia Social and Behavioral Sciences 19 (2011) 556-566.

Bahari, R.A., Abbaspour, R.A., Pahlavani, P., 2014, November. Prediction of PM2.5 concentrations using temperature inversion effects based on an artificial neural network. In The ISPRS international conference of Geospatial information research (Vol. 15, p. 17).

Baidya, P., et al. (2014) Effectiveness of Fuzzy Overlay Function for Multi-Criteria Spatial Modeling-A Case Study on Preparation of Land Resources Map for Mawsynram Block of East Khasi Hills District of Meghalaya, India. Journal of Geographic Information System, 6, 605-612.

Bigdeli, B., Samadzadegan, F., Reinartz, P., 2013. Classifier fusion of hyperspectral and lidar remote sensing data for improvement of land cover classifcation. International Archives of the Photogrammetry, Remote Sensing and Spatial Information Sciences, 1, p.W3.

Bigdeli, B., Samadzadegan, F., Reinartz, P., 2014. Feature grouping-based multiple fuzzy classifier system for fusion of hyperspectral and LIDAR data. Journal of Applied Remote Sensing, 8(1), p.083509.

Bonham-Carter G (1994) Geographic information systems for geoscientists. Pergamon, New York.

Buchele, B., et al. 2006. Flood-risk mapping: contributions towards an enhanced assessment of extreme events and associated risks. Natural Hazards and Earth System Sciences No.6, PP: 485-503.

Chang, D.Y., 1996. Applications of the extent analysis method on fuzzy AHP. European Journal of Operational Research 95 pp. 649-655.

Cheng, C.H. 1997. Evaluating naval tactical systems by fuzzy AHP based on the grade value of membership function. European Journal of Operational Research No.96, PP: 343-350.

Correia, E.N., M.G. Saraiva, F.N. Silva and I. Romos. 1999. Floodplain Management in Urdan Development Area. Part II. GIS-Based Flood Analysis and Urdan Growth Modeling. February 1999, Volume 13, Issue 1, pp: 23-37.

Delavar, M.R., Samadzadegan, F., Pahlavani, P., 2004. A GISAssisted optimal urban route finding approach based on genetic algorithms. International archives of photogrammetry remote sensing and spatial information sciences, 35(Part 2), pp.305-308.

Deng, H., 1999. Multicriteria analysis with fuzzy pairwise comparisons, Int. J. Approximate Reasoning 21, pp. 215-231.

Erensal, Y.C., Oncan, T., Demircan, M.L., 2006. Determining key capabilities in technology management using fuzzy analytic hierarchy process: A case study of Turkey. Information Sciences 176 , pp. 2755-2770.

Fernandez, D.S., M.A., Lutz. 2010. Urban flood hazard zoning in Tucumán Province Argentina, using GIS and multicriteria decision analysis. Engineering Geology No.111, PP: 90-98.

Gamper, C., M., Thöni, H., Weck-Hannemann. 2006. A conceptual approach to the use of cost benefit and multi criteria analysis in natural hazard management. Natural Hazards and Earth System Sciences N0.6, PP: 293-302.

Hansen, H.S., 2005. GIS-based Multi-Criteria Analysis of Wind Farm Development. In: Hauska, H. \& Tveite, H. (Eds.) ScanGIS'2005. Proceedings of the 10th Scandinavian Research Conference on Geographical Information Science, Stockholm, Sweden, Royal Institute of Technology, pp. 75-87.

Hersh, H.M., Caramazza, A., and Brownell, H.H. 1979. Effects of context on fuzzy membership functions. In Gupta et al. 389408 .

Hyalmarson, H.W. 1988. Flood Hazard Zonation in Aridland. Wesley Publishers, 114 pp.

Islam, M.D. and S. Kimitero. 2000. Development of Flood Hazard Maps of Bangladesh Using NOAA-AVHRR Images with GIS. Hydrological Sciences Journal, 45: 42-48.

Liang, S. and C.R.C. Mohanty. 1997. Optimization of GIS-Based Flood Hazard Zoning a Case Study at the Mahanady Command Area in Cuttack District, Orrisa, India. Journal of Chinese Soil and Water Conservation, 28: 11-20.

Maantay, J., A., Maroko. 2009. Mapping urban risk: Flood hazards, race, \& environmental justice in New York, Applied Geography No.29, PP: 111-124.

Mikhailov, L., Tsvetinov, P., 2004, Evaluation of services using a fuzzy analytic hierarchy process. Applied Soft Computing 5, pp. 23-33.

Morelli, S., et al. 2012. Urban planning, flood risk and public policy: The case of the Arno River, Firenze, Italy, Applied Geography No.34, PP: 205-218.

Ozturk, D. and F. Batuk. 2011. Implementation of Gis-Based Multicriteria Decision Analysis with Va in ArcGic. International Journal of Information Technology \& Decision Making, 6: 10231042.

Pahlavani, P., Samadzadegan, F., Delavar, M.R., 2006, September. A GIS-based approach for urban multi-criteria quasi optimized route guidance by considering unspecified site satisfaction. In International Conference on Geographic Information Science (pp. 287-303). Springer, Berlin, Heidelberg.

Pahlavani, P., Sheikhian, H., Bigdeli, B., 2017. Assessment of an air pollution monitoring network to generate urban air pollution maps using Shannon information index, fuzzy overlay, and Dempster-Shafer theory, A case study: Tehran, Iran. Atmospheric environment, 167, 254-269.

Rashed, T., J., Weeks. 2003. Assessing social vulnerability to earthquake hazards through spatial multi criteria analysis of urban areas. International Journal of Geographic Information Science No.17 (6), PP: 549-576. 